\title{
Results of three to 10 year follow up of balloon dilatation of the pulmonary valve
}

\author{
P S Rao, O Galal, M Patnana, S H Buck, A D Wilson
}

\begin{abstract}
Background-The results of immediate and short term follow up of balloon dilatation of the pulmonary valve have been well documented, but there is limited information on long term follow up.

Objective-To evaluate the results of three to 10 year follow up of balloon dilatation of the pulmonary valve in children and adolescents.
\end{abstract}

Setting-Tertiary care centre/university hospital.

Design-Retrospective study.

Methods and results -85 patients (aged between 1 day and 20 years, mean (SD) 7.0 (6.4) years) underwent balloon dilatation of the pulmonary valve during an 11 year period ending August 1994. There was a resultant reduction in the peak to peak gradient from 87 (38) to 26 (22) $\mathrm{mm} \mathrm{Hg}$. Immediate surgical intervention was not required. Residual gradients of 29 (17) $\mathrm{mm} \mathrm{Hg}$ were measured by catheterisation $(n=47)$ and echo Doppler $(n=82)$ at intermediate term follow up (two years). When individual results were scrutinised, nine of 82 patients had restenosis, defined as a peak gradient of $50 \mathrm{~mm} \mathrm{Hg}$ or more. Seven of these patients underwent repeat balloon dilatation of the pulmonary valve: peak gradients were reduced from 89 (40) to 38 (20) $\mathrm{mm} \mathrm{Hg}$. Clinical evaluation and echo Doppler data of 80 patients showed that residual peak instantaneous Doppler gradients were 17 (15) $\mathrm{mm} \mathrm{Hg}$ at long term follow up (three to 10 years, median seven), with evidence for late restenosis in one patient $(1.3 \%)$. Surgical intervention was necessary to relieve fixed infundibular stenosis in three patients and supravalvar pulmonary stenosis in one. Repeat balloon dilatation was performed to relieve restenosis in two patients. Actuarial reintervention free rates at one, two, five, and 10 years were $94 \%, 89 \%, 88 \%$, and $84 \%$, respectively. Pulmonary valve regurgitation was noted in 70 of 80 patients at late follow up, but neither right ventricular dilatation nor paradoxical interventricular septal motion developed.

Conclusions-The results of late follow up of balloon dilatation of the pulmonary valve are excellent. Repeat balloon dilatation was performed in $11 \%$ of patients and surgical intervention for subvalvlar or supravalvar stenosis in $5 \%$. Most patients had mild residual pulmonary regurgitation but right ventricular volume overload did not develop and surgical intervention was not required. Balloon dilatation is the treatment of choice in the management of moderate to severe stenosis of the pulmonary valve. Further follow up studies should be undertaken to evaluate the significance of residual pulmonary regurgitation.

(Heart 1998;80:591-595)

Keywords: balloon dilatation of the pulmonary valve; pulmonary stenosis; pulmonary regurgitation

Since the first description of balloon dilatation of the pulmonary valve by Kan et al, ${ }^{1}$ her group ${ }^{2}$ and others have used this technique for the relief of stenosis of the pulmonary valve in neonates, infants, and children. Immediate and short term results have been well documented (an extensive reference list of publications reporting the results of immediate and intermediate term follow up is available from the corresponding author). However, there are limited data on long term follow up (more than five years). The purpose of this study was to evaluate the results of long term follow up of balloon dilatation of the pulmonary valve in children and adolescents. We also examined the development of restenosis and pulmonary valve regurgitation during late follow up and reintervention free rates following balloon dilatation.

\section{Patients and methods}

The series comprised 85 consecutive children and adolescents (aged between 1 day and 20 years) who underwent balloon dilatation of the pulmonary valve during an 11 year period ending August 1994. Fifty eight procedures were performed at the King Faisal Specialist Hospital and Research Center, Riyadh, Saudi Arabia and 27 at the University of Wisconsin Children's Hospital, Madison, Wisconsin, USA. Immediate and short term results of the first 56 children have been reported, ${ }^{3}$ but the results of long term follow up have not been published.

INCLUSION AND EXCLUSION CRITERIA

Patients who fulfilled the following criteria were selected for balloon dilatation of the pulmonary valve: a peak to peak systolic pressure gradient across the pulmonary valve of $50 \mathrm{~mm} \mathrm{Hg}$ or greater with a normal cardiac index irrespective of symptoms. ${ }^{5}$ Patients who underwent balloon dilatation of the pulmonary valve for palliation of cyanosis and pulmonary oligaemia secondary to stenosis of the pulmonary valve associated with a large interventricular communication ${ }^{67}$ were excluded. However,
Accepted for publication 10 July 1998 
Table 1 Grading of pulmonary regurgitation by echo Doppler studies

\begin{tabular}{|c|c|}
\hline None & pulmonary regurgitation on Doppler study \\
\hline Grade I & $\begin{array}{l}\text { ulmonary regurgitation jet width } \leqslant 10 \% \text { of pulmonary valve annulus diameter } \\
\text { precordial short axis view } \\
\text { o right ventricle volume overload }\end{array}$ \\
\hline Grade II & $\begin{array}{l}\text { ulmonary regurgitation jet width } 11-25 \% \text { of pulmonary valve annulus diameter } \\
\text { lo right ventricle volume overload }\end{array}$ \\
\hline Grade III & $\begin{array}{l}\text { Pulmonary regurgitation jet width } 26-50 \% \text { of pulmonary valve annulus diameter } \\
\text { No right ventricle volume overload but with or without flat septal motion }\end{array}$ \\
\hline Grade 1 & $\begin{array}{l}\text { Pulmonary regurgitation jet width }>50 \% \text { of pulmonary valve annulus diameter } \\
\text { Right ventricle volume overload present }\end{array}$ \\
\hline
\end{tabular}

Jet width at the origin of regurgitation jet rather than jet length was used for grading because the jet width is not influenced by pulmonary artery pressures.

Right ventricle volume overload is defined as enlarged right ventricle ( $>95$ percentile) and flat to paradoxical septal motion.

patients with an associated atrial septal defect or patient foramen ovale with right to left atrial shunt ${ }^{7}$ were included.

TECHNIQUE

Informed consent was obtained from the parents of each patient. Children old enough to understand were asked for their consent. The technique of balloon dilatation of the pulmonary valve that was used has been described in detail,$^{89}$ and is similar to that performed by others. $^{210}$ The size of the balloon was within

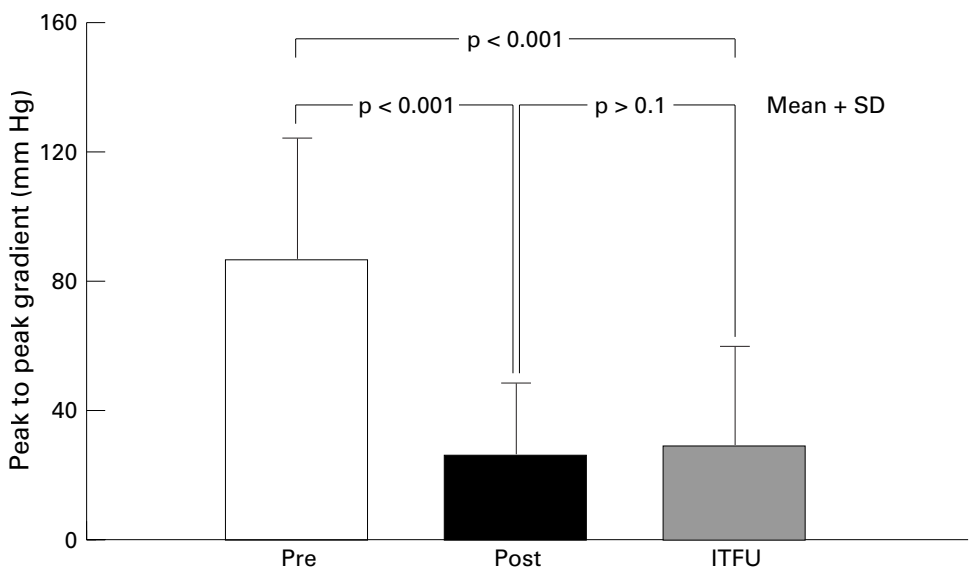

Figure 1 Mean (SD) peak to peak systolic pressure gradients measured at cardiac catheterisation before (Pre) and after (Post) balloon dilatation of the pulmonary valve. There is a significant decrease $(p<0.001)$ immediately following dilatation. The gradient measured during repeat catheterisation in 47 patients at intermediate term follow up (ITFU) is unchanged $(p>0.1)$ compared with the gradient immediately after dilatation and continues to be lower $(p<0.001)$ than the gradient before dilatation.

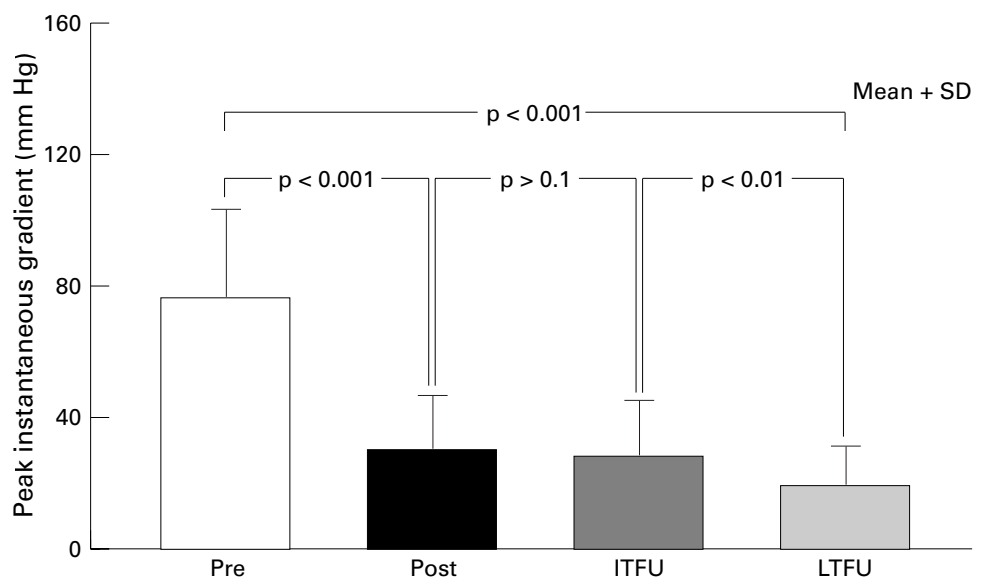

Figure 2 Mean (SD) maximum peak instantaneous Doppler gradients measured before (Pre) and one day after (Post) balloon dilatation of the pulmonary valve and at intermediate (ITFU) and late (LTFU) term follow up. There is a reduction $(p<0.001)$ after dilatation that remains unchanged $(p>0.1)$ at ITFU. At LTFU, however, there was further fall $(p<0.01)$.
1-2 $\mathrm{mm}$ of the size of the pulmonary valve annulus in the initial part of the study. Subsequent to reports of the usefulness of larger balloons ${ }^{11-13}$ an attempt was made to achieve a balloon/annulus ratio between 1.2 and 1.4. A double balloon technique ${ }^{111415}$ was used in 12 patients $(14 \%)$.

FOLLOW UP

Follow up included clinical evaluation and echo Doppler studies at day 1 and 3, six, and 12 months after balloon dilatation and yearly thereafter. Clinical evaluation focused on symptoms and the need for reintervention. Echo Doppler assessed the maximum peak instantaneous gradient across the pulmonary valve $^{1617}$ and pulmonary regurgitation. The results of pulmonary regurgitation were semiquantitated by modification of the criteria described by Cooper et al (table 1). ${ }^{18}$ The size of the right and left ventricles were also measured and $\mathrm{M}$ mode echocardiograms were evaluated for abnormalities of interventricular septal motion. Forty seven patients (55\%) underwent cardiac catheterisation at a mean (SD) of 9 (4) months after balloon dilatation of the pulmonary valve. Catheterisation was performed in most patients in the first half of the study, whereas this procedure was carried out in only selected patients thereafter.

STATISTICAL METHODS

Data are expressed as means (SD) for continuous, normally distributed variables. Medians (range) are given when the data are not normally distributed. Values before and after balloon dilatation were compared by two tailed or paired $t$ tests, or an appropriate nonparametric analogue. Independent sample $t$ tests were used for between group comparisons of normally distributed variables. Fisher's exact, Kruskal-Wallis, McNemars, or MannWhitney tests were used, as appropriate, for between group comparisons of categorical, ordinal, or not normally distributed variables. Multivariate logistic regression analysis was performed to identify predictors of restenosis of the pulmonary valve. Actuarial analysis of event free rates were calculated by the KaplanMeir method. Statistical significance was set at $\mathrm{p}<0.05$ and adjusted using Bonferroni's technique when multiple comparisons were made.

\section{Results}

\section{PATIENTS}

Eighty five patients (43 male) with a weight range of $2.9-75 \mathrm{~kg}$ (mean (SD) 21 (16) $\mathrm{kg}$ ) underwent balloon dilatation of the pulmonary valve. The mean (SD) age was 7.0 (6.4) years; seven were neonates, 15 were between 1 and 12 months, 35 were between 1 and 10 years old, and the remaining 28 were between 11 and 20 years old. There were no associated cardiac defects in 39 patients (46\%); a patent foramen ovale was present in $38(45 \%)$. In the remaining eight children tiny patent ductus arteriosus were present in two, persistent left superior vena cava in two, moderate to severe tricuspid regurgitation in two, Ebstein's anomaly of the tricuspid valve in one, and stenosis of the right 


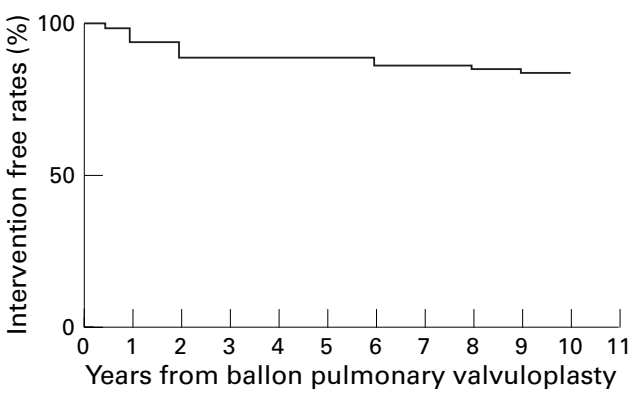

Figure 3 Actuarial event free rates after balloon dilatation of the pulmonary valve. Reintervention free rates at one, two, five, and 10 years are $94 \%, 89 \%, 88 \%$, and $84 \%$, respectively.

pulmonary artery in one. Three children (3.5\%) had previously undergone surgical valvotomy of the pulmonary valve approximately one year before balloon dilatation. One child $(1.2 \%)$ had Noonan's syndrome.

IMMEDIATE AND INTERMEDIATE TERM FOLLOW UP The peak to peak systolic pressure gradient was reduced by catheter pullback across the pulmonary valve (fig 1) immediately following balloon dilatation of the pulmonary valve and at intermediate follow up (defined as two years or less) (fig 1). The maximum peak instantaneous Doppler gradient also declined immediately following balloon dilatation and at intermediate term follow up (fig 2). These findings are similar to those reported previously. ${ }^{3489}$ When the results of individual patients were scrutinised, nine $(11 \%)$ of 82 patients had restenosis defined as a gradient of $50 \mathrm{~mm} \mathrm{Hg}$ or more at intermediate term follow up. Seven of these patients underwent repeat balloon dilatation of the pulmonary valve at a mean interval of 12 months after initial balloon dilatation: peak to peak gradients were reduced from 89 (40) to 38 (20) $\mathrm{mm} \mathrm{Hg}(\mathrm{p}<0.01)$. Predictors of restenosis were identified by multivariate stepwise logistic regression analysis as described previously ${ }^{19}$ : a balloon/annulus ratio of less than 1.2 and a pulmonary valve gradient of $30 \mathrm{~mm} \mathrm{Hg}$ immediately following dilatation, as observed in our initial study. ${ }^{19}$ The prevalence, management, and resolution of in-

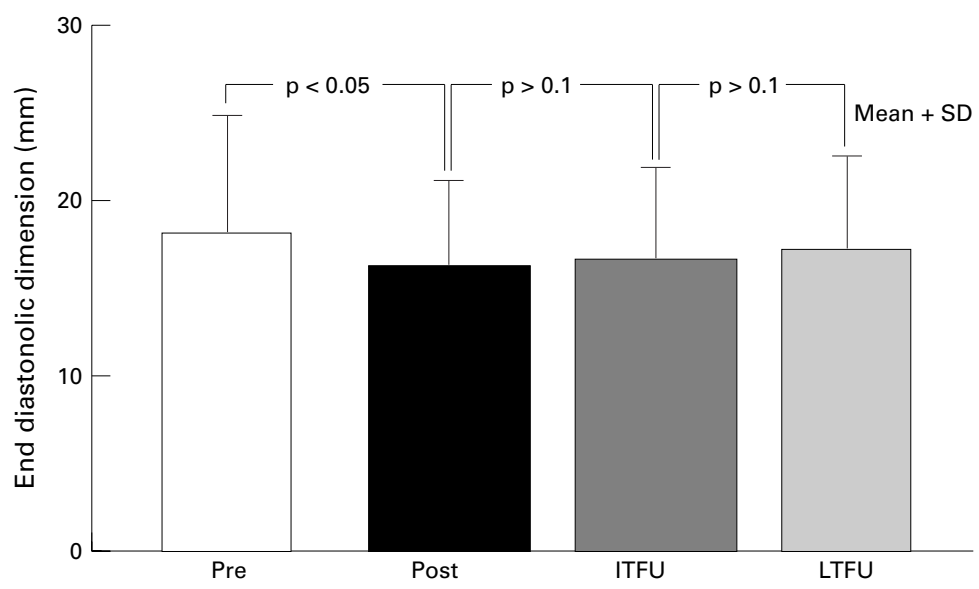

Figure 4 Right ventricular end diastolic dimensions before (Pre) and one day after (Post) balloon dilatation of the pulmonary valve and at intermediate (ITFU) and late (LTFU) term follow up. There was a significant decrease $(p<0.05)$ in right ventricular size immediately following balloon dilatation. There was no further change at ITFU and LTFU. fundibular obstruction were similar to those described in our previous report ${ }^{20}$ except for the requirement for surgery: two additional children required reintervention during intermediate term follow up: both had surgical resection of severe, fixed infundibular pulmonary obstruction at two months and two years, respectively, after dilatation.

\section{LATE FOLLOW UP}

Three to 10 year follow up (median seven years) was available in 80 patients. Five patients were lost to follow up: there was no evidence of obstruction at the last available follow up. None of the 80 patients had symptoms referable to the cardiovascular system.

\section{Residual gradients}

The maximum peak instantaneous gradient at long term follow up evaluation was 17 (15) $\mathrm{mm} \mathrm{Hg}$, significantly lower $(\mathrm{p}<0.01)$ than the gradients seen before balloon dilatation and at intermediate term follow up (fig 2).

\section{Reintervention}

Four children ( $5 \%$ ) who had no reintervention during intermediate term follow up required reintervention during late follow up. One child underwent surgery for severe supravalvar pulmonary stenosis and secundum atrial septal defect 36 months after balloon dilatation. Another child had severe, fixed infundibular obstruction 102 months after balloon dilatation. The third child underwent repeat balloon dilatation of the pulmonary valve 93 months after initial balloon dilatation. This child had a gradient of $52 \mathrm{~mm} \mathrm{Hg}$ during intermediate term follow up, but did not undergo repeat intervention. The fourth child developed late restenosis with a gradient of $71 \mathrm{~mm} \mathrm{Hg}$, requiring repeat balloon dilatation 66 months after initial balloon dilatation. Actuarial event free rates (fig 3) suggest that $94 \%, 89 \%, 88 \%$, and $84 \%$ of patients are free from reintervention at one, two, five, and 10 year follow up.

\section{Ventricular dimensions}

The right ventricular end diastolic dimension (mean (SD) $17.2(5.4) \mathrm{mm}$ ) was similar $(p>0.1)$ to dimensions before balloon dilatation and at intermediate term follow up (fig 4). None of the patients had an enlarged right ventricle compared with normal values for the square root of body surface area. ${ }^{21}$ The left ventricular end diastolic dimension (mean (SD) $37.0(7.8) \mathrm{mm})$ was increased $(\mathrm{p}<0.01)$ compared with the dimension before dilatation (29.3 (8.6) $\mathrm{mm}$ ), reflecting growth in ventricular size with increasing patient age. The values are within the normal range when normalised to the square root of body surface area. ${ }^{21}$

\section{Pulmonary regurgitation}

The incidence of pulmonary regurgitation by Doppler was higher $(\mathrm{p}<0.001)$ at late follow up (fig 5A); there was gradual increase in the number of patients with pulmonary regurgitation. In addition, there was an increase in the number of patients with flat interventricular septal motion (fig 5B). However, none had 

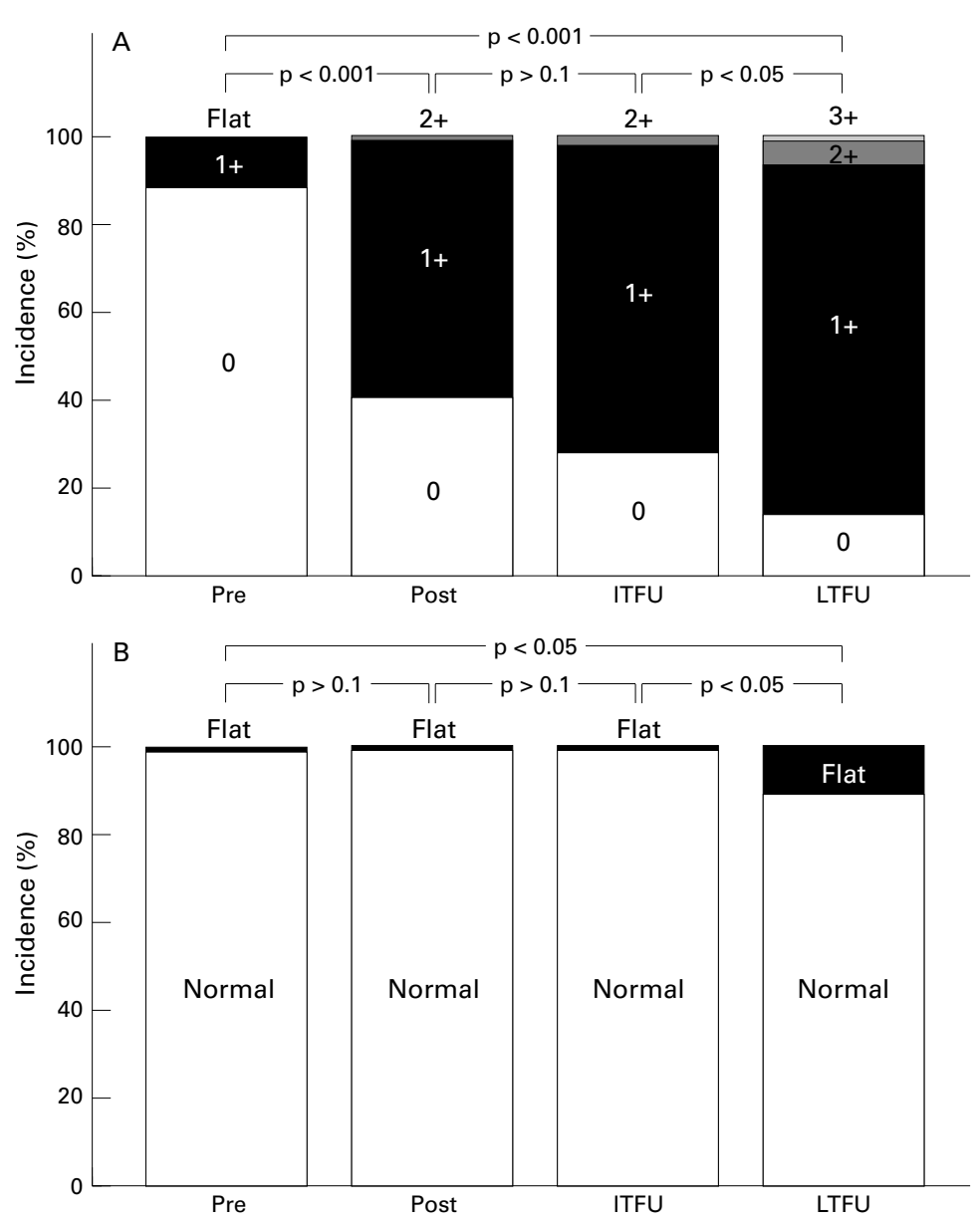

Figure 5 (A) Doppler graded (table) pulmonary regurgitation before (Pre) and one day after (Post) balloon dilatation of the pulmonary valve and at intermediate (ITFU) and late (LTFU) term follow up. There is a gradual but significant increase $(p<0.05$ to $p<0.001)$ in the incidence of pulmonary regurgitation. (B) Nature of interventricular septal motion. There is a significant increase $(p<0.05)$ in the incidence of flat septal motion at LTFU. None of the patients had paradoxical septal motion.

paradoxical septal motion. On the basis of a lack of right ventricular dilatation and the absence of paradoxical septal motion, none of the patients was considered to have significant pulmonary regurgitation. Surgical intervention for treatment of pulmonary regurgitation was not required.

\section{Discussion}

FOLLOW UP STUDIES

This study reports the results of long term follow up (three to 10 years) in 80 patients who underwent balloon dilatation of the pulmonary valve before August 1994. There is evidence for minimal restenosis beyond what was observed at intermediate term follow up (11\%) and residual gradients are low at $17(15) \mathrm{mm} \mathrm{Hg}$. Actuarial reintervention free rates were $88 \%$ at five years and $84 \%$ at 10 years after balloon dilatation. The incidence of pulmonary regurgitation increased but the condition was not severe and surgical intervention was not required.

Immediate and intermediate term results of balloon dilatation of the pulmonary valve for relief of congenital stenosis of the pulmonary valve have been reported by several workers (referenced extensively elsewhere). ${ }^{92}$ The re- sults of long term follow up have not been reported; results of the longest follow up periods were 4.9 and 5.3 years. ${ }^{23}{ }^{24} \mathrm{McC}$ Crindle and $\mathrm{Kan}^{23}$ reported the results of a 4.9 year (mean) follow up of 46 patients. They found a residual peak instantaneous Doppler gradient of 20 (13) $\mathrm{mm} \mathrm{Hg}$. The incidence of mild pulmonary regurgitation was $80 \%$. O'Connor et al reported the results of a 5.3 year (mean) follow up of 20 patients. $^{24}$ They found a residual follow up Doppler gradient of 24 (3) $\mathrm{mm} \mathrm{Hg}$. The incidence of mild pulmonary regurgitation was $45 \%$. These results as well as our own data, reported herein, suggest that residual gradients remain low at late follow up, but with a higher incidence of pulmonary regurgitation.

\section{COMPARISON WITH SURGERY}

Comparison of follow up results of surgical valvotomy versus balloon dilatation is problematic in that: (1) the number of available patients who undergo balloon dilatation of the pulmonary valve at follow up is small; (2) the duration of available follow up after balloon dilatation is relatively short; and (3) there are problems inherent in comparing "older" historical surgical results with those of "current" balloon dilatation. In a previous review ${ }^{9}$ in which we compared the results derived from nine representative surgical reports with those from 11 reports of treatment with balloon dilatation mortality and morbidity seemed to be greater after surgery; however, the recurrence rate was higher following balloon dilatation.

O'Conner et al who compared the results of balloon dilatation of the pulmonary valve $(n=20)$ with those of an age and gradient matched surgical control group found slightly higher Doppler peak instantaneous gradients in the balloon group (24 (2.7) $\mathrm{mm} \mathrm{Hg}$ ) than in the surgical controls $(16(1.5) \mathrm{mm} \mathrm{Hg}){ }^{24}$ The incidence of mild pulmonary regurgitation was $45 \%$ in the balloon group, while the incidences of mild and moderate pulmonary regurgitation were $45 \%$ and $45 \%$, respectively, in the surgical controls. Follow up duration was significantly shorter (5.3 (0.3) v $11.7(0.5)$ years) in the balloon group than in the surgical controls, thus making it difficult to interpret the data, a problem similar to that described in the aforementioned review. ${ }^{9}$

The advantages of balloon dilatation in terms of morbidity and mortality ${ }^{9}$ are clear. The degree of pulmonary regurgitation also seems to be better following balloon dilatation than after surgery. ${ }^{24}$ The recurrence rate seems to be higher ${ }^{9}$ with balloon dilatation than with surgical treatment. Initially, most workers used small balloons (balloon/annulus ratio approximately 1.0); however, after data on larger balloons became available ${ }^{11-13}$ many workers started using large balloons to achieve a balloon/annulus ratio between 1.2 and 1.4. Indeed, recurrences were not found when we examined the results of patients who underwent balloon dilatation with a balloon larger than 1.2 times the valve annulus. ${ }^{13}$ It is likely that balloon treatment is better than surgery, especially when the balloon/annulus ratio is between 1.2 and 1.4 . 
CONCLUSION

Balloon dilatation of the pulmonary valve produces excellent immediate gradient relief in children and adolescents with stenosis of the pulmonary valve. While gradient relief is maintained for the group as a whole at intermediate term follow up, restenosis $(11 \%)$ was found when the results of individual patients were reviewed. Repeat balloon dilatation gave excellent relief of obstruction. At late follow up (three to 10 years), there is evidence for additional minimal restenosis, but the incidence of pulmonary regurgitation is increased. Right ventricular volume overload did not develop and surgical intervention was not required. Actuarial event free rates were $88 \%$ at five years and $84 \%$ at 10 years. On the basis of these data, we conclude that balloon dilatation of the pulmonary valve is the treatment of choice in the management of isolated stenosis of the pulmonary valve. Careful longer term follow up (10-20 years) to evaluate the significance of pulmonary regurgitation should be continued.

The authors thank Drs M E Fawzy, F Kutayli, J M Levy, M K Mardini, L Solymar, and M K Thapar for their contributions to the clinical material. We also thank Mr J Hormann and Ms K Thompson for assistance with the statistical analysis and preparation of the manuscript.

1 Kan JS, White RI, Jr, Mitchell SE, et al. Percutaneous balloon valvuloplasty: a new method for treating congenital pulmonary valve stenosis. $N$ Engl f Med 1982;307:540-2.

2 Kan JS, White RI, Jr, Mitchell SE, et al. Percutaneous transluminal balloon valvuloplasty for pulmonary valve stenosis. Circulation 1984;69:554-60.

3 Rao PS, Fawzy ME, Solymar L, et al. Long-term results of balloon pulmonary valvuloplasty of valvar pulmonic stenosis. Am Heart F 1988;115:1291-6.

4 Rao PS. Balloon pulmonary valvuloplasty: a review. Clin Cardiol 1989;12:55-74.

5 Rao PS. Indications for balloon pulmonary valvuloplasty [editorial]. Am Heart f 1988;116:1661-2.

6 Rao PS, Brais M. Balloon pulmonary valvuloplasty for congenital cyanotic heart defects. Am Heart $\mathcal{f}$ 1988;115: 1105-10.
7 Rao PS, Wilson AD, Thapar MK, et al. Balloon pulmonary valvuloplasty in the management of cyanotic congenital heart defects. Cathet Cardiovasc Diagn 1992;25:16-24.

8 Rao PS, Mardini MK. Pulmonary valvotomy without thoracotomy: the experience with percutaneous balloon pulmonary valvuloplasty. Ann Saudi Med 1985;5:149-55.

9 Rao PS. Balloon pulmonary valvuloplasty for isolated pulmonary stenosis. In: Rao PS, ed. Transcatheter therapy in pediatric cardiology. New York: Wiley-Liss, 1993:59-104.

10 Lababidi Z, Wu Jr. Percutaneous balloon pulmonary valvuloplasty. Am f Cardiol 1983;52:560-2.

11 Rao PS. Influence of balloon size on the short-term and long-term results of balloon pulmonary valvuloplasty. Tex Heart Inst f 1987;14:57-61.

12 Radtke W, Kane JL, Fellows KE, et al. Percutaneous balloon valvotomy of congenital pulmonary stenosis using oversized balloons. F Am Coll Cardiol 1986;8:909-15.

13 Rao PS. Further observations on the effect of balloon size on the short-term and intermediate term results of balloon dilatation of the pulmonary valve. Br Heart f 1988;60:507-11.

14 Mullins CE, Nihill MR, Vick GW III, et al. Double balloon technique for dilatation of valvar or vessel stenosis in congenital or acquired heart disease. $\mathcal{F} \mathrm{Am}$ Coll Cardiol 1987;10:107-14.

15 Rao PS, Fawzy ME. Double balloon technique for percutaneous balloon pulmonary valvuloplasty: comparison with single balloon technique, f Intervent Cardiol 1988;1:257-62.

16 Rao PS. Value of echo-Doppler studies in the evaluation of the results of balloon pulmonary valvuloplasty. $\mathcal{F}$ Cardiovasc Ultrasonography 1986;5:309-12.

17 Rao PS. Doppler ultrasound in the prediction of transvalvar pressure gradients in patients with valvar pulmonic stenosis. Int $\mathcal{F}$ Cardiol 1987;15:195-203.

18 Cooper J, Fan P, Chopra HK, et al. Conventional and color Doppler assessment of right-sided valvar regurgitation. In: Nanda NK, ed. Textbook of color Doppler echocardiography. Philadelphia: Lea and Febiger, 1989:160-7.

19 Rao PS, Thapar MK, Kutayli F, et al. Causes of restenosis following balloon valvuloplasty for valvar pulmonic stenosis. Am $\mathcal{f}$ Cardiol 1988;62:979-82.

20 Thapar MK, Rao PS. Significance of infundibular obstruction following balloon valvuloplasty for valvar pulmonic stenosis. Am Heart f 1989;118:99-103.

21 Gutgesell HP, Rembold CM. Growth of human heart relative to body surface area. Am f Cardiol 1990;65:662-8.

22 Rao PS. Transcatheter treatment of pulmonary outflow tract obstruction: a review. Prog Cardiovasc Dis 1992;35: $119-58$.

23 McCrindle B, Kan J. Long-term results after balloon pulmonary valvuloplasty. Circulation 1991;83:1915-22.

24 O'Connor BK, Beekman RH, Lindaur A, et al. Intermediate-term outcome after pulmonary balloon valvuloplasty: comparison with a matched surgical group. $\mathcal{F}$ Am Coll Cardiol 1992;20:169-73. 